\title{
The Effect of Engagement and Perceived Course Value on Deep and Surface Learning Strategies
}

\author{
Kevin S. Floyd, Susan J. Harrington, and Julie Santiago \\ Macon State College, Macon, Georgia, U.S.A
}

\author{
kevin.floyd@maconstate.edu; sue.harrington@maconstate.edu; \\ julie.santiago@maconstate.edu
}

\begin{abstract}
This study investigated the relationships among perceived course value, student engagement, deep learning strategies, and surface learning strategies. The study relied on constructs from previous studies to measure course value, engagement, surface learning strategy, and deep learning strategy. Statistically significant findings were observed between perceived course value, student engagement, and deep learning strategy. Surface learning strategies occur when the student's perceived value of the course is low. These findings suggest that deep learning strategies occur when students are engaged in the learning process and their perceived value of the course content is high. While there is much research to support the finding that engagement is a way to help students learn, the findings of this study show that course value has a greater positive influence on deep learning and surface learning strategies than engagement. By understanding and enhancing perceived value and engagement, the ultimate goal of enhancing deep learning should result.
\end{abstract}

Keywords: learning styles, deep learning, surface learning, student engagement, course value, education (relevance)

\section{Introduction}

Colleges and universities are spending much time and effort to provide their students with the best educational experience possible. This effort becomes particularly important when framed within the idea that students usually have more than one choice for their college career, leading to competition between higher education institutions. In order to make their programs more attractive to current and potential students, many colleges and universities have begun a fundamental shift in how their classes are conducted. Often, these institutions have moved away from the traditional lecture-based pedagogy in favor of more active, learner-centered activities. It is believed that more learner-centered and collaborative activities will enhance a student's learning experi-

ence. Though a positive learning ex-

Material published as part of this publication, either on-line or in print, is copyrighted by the Informing Science Institute. Permission to make digital or paper copy of part or all of these works for personal or classroom use is granted without fee provided that the copies are not made or distributed for profit or commercial advantage AND that copies 1) bear this notice in full and 2) give the full citation on the first page. It is permissible to abstract these works so long as credit is given. To copy in all other cases or to republish or to post on a server or to redistribute to lists requires specific permission and payment of a fee. Contact Publisher@InformingScience.org to request redistribution permission. perience could be defined by a number of factors, engagement, perceived course value, and the use of deep learning strategies are believed to be integral to a student's positive learning experience.

One of the most important and often researched factors that contribute to a student's course experience is engagement. Though numerous studies have 
examined student engagement and a complete examination of this topic is beyond the scope of this paper, Corno and Mandinach (1983) were the first researchers to define and examine student cognitive engagement. They proposed that student engagement was evident when students demonstrated prolonged attention to a mentally challenging task, resulting in authentic learning and increased levels of higher order thinking. Indeed, Conrad and Donaldson (2004) stated that critical thinking is a result of high levels of engagement.

Richardson and Newby (2006) defined cognitive engagement as the integration and utilization of students' motivations and strategies in the course of their learning. In their study, an engaged student is a motivated student. They focused on which motivations and learning strategies lead to cognitive engagement in order to properly manipulate the learning environment to encourage the students' engagement. By understanding effective ways in which the instructor (the informer) can frame the message to the student (the client), the instructor (the informer) may be able to enhance the student's (the client's) motivation to receive the message (cf. Cohen, 2009).

Hidi and Renninger (2006) propose a four-phase model of interest development that affects learning and engagement. Each phase is characterized by varying amounts of affect, knowledge, and value. Sustained interest is achieved either by support from others or by the challenge or opportunity provided by the task to be learned. Hidi and Renninger (2006) believe that the potential for interest is in the person, but the environment and content define the direction of interest and influence its development. Early phases of interest development tend to be affective because they consist of focused attention and positive feelings. Later phases of interest development continue to consist of positive feelings but also include sustained value and knowledge. Indicators of later phases of interest are the student's repeated engagement and knowledge.

Student biases can act as filters on information received (Jamieson \& Hyland, 2006). For example, information biases are believed to modify incoming information to align it with the client's (student's) preferences. The Single Client Resonance Model proposed by Gill (2008) explains that a series of filters affects a student's (client's) knowledge at three levels, from high level concepts at one extreme (Level 3) to lower, more automated operators at the other extreme (Level 1). An in-depth understanding of high level concepts (deep learning) can be reached when attention (engagement) and motivation are present. The process of engagement is as an important a factor in informing our clients (students) as the quality and usefulness of the task at hand.

Initial interest in learning can be triggered by personal relevance (Hidi \& Renninger, 2006). Continued interest can be sustained by meaningfulness of tasks or personal involvement, such as project-based learning or one-on-one tutorials. However individual interest may diminish if not supported, and true engagement may not result. Well-developed individual interest tends to be psychologically based and affective but is still facilitated by instructional conditions, such as opportunities for interaction. Only personal involvement and meaningfulness of tasks has been found to maintain the student's interest over time (Mitchell, 1993). Hulleman (2007) found that a relevance intervention, where students were encouraged to apply the course material to their own lives, increased perception of value, leading to increased interest and classroom performance, particularly among students with lower levels of belief in their abilities.

Therefore, it is clear that, in addition to engagement, the students' perception of course value, in the form of personal relevance and meaningfulness of tasks, is a very important concept in enhancing and evaluating a student's learning experience. Course value has been found to be intrinsic, where the course is enjoyable and fun, or utilitarian, where the course is perceived as useful or important to other tasks or aspects of an individual's life (Hulleman, 2007). Intrinsic and utility value can be perceived almost immediately upon beginning a learning task and can lead to situational interest (Hidi \& Renninger, 2006). Simulating real-world projects can assist the student in identifying learning goals and can generate increased motivation and learning (Jurow, 2005). Pre- 
vious findings support that students find value in courses that use active approaches to studying relevant curriculum (Bishop \& Pflaum, 2005). A student's perception of course value is distinct from engagement in that a student may find the course of value but not be fully engaged in its content. Theory suggests that perception of course value facilitates engagement and that perception of course value and engagement lead to deep learning.

Marton and Säljö (1976) first introduced the idea of deep learning. Deep learning implies the demonstration of higher order thinking skills such as synthesis and evaluation, and a personal commitment to learn the material, not merely learning for the sake of a passing grade (Biggs, 1987; Entwistle, 1981; Ramsden, 2003; Tagg, 2003). Surface learning, on the other hand, is associated more with rote learning and the desire to earn a passing grade (Biggs, 1989; Bowden \& Morton, 1998; Draper, 2009; Tagg, 2003). Students who use a surface learning strategy are trying to avoid failure with the minimum amount of effort and involvement (Cano, 2007). Draper (2009) expanded upon this idea by concluding that shallow learners understand the material correctly, but simply do not possess the connections between concepts that deep learners do. Deep learners can transfer the learned concepts to a variety of situations thereby creating a denser matrix of connections within their knowledge and understanding. Therefore, the student's motive is integral to whether he or she engages in deep or surface learning strategies.

Though there are a number of factors related to students' cognitive engagement and perception of course value, learning strategies are among the most important. While cognitive engagement and perception of course value suggest motives for learning, learning strategies are what the students do relative to those motives (Biggs, 1987). Deep and surface learning strategies are motivated by different factors and would be expected to move in a coherent pattern in relationship to each other: students who use deep learning strategies would tend not to use surface strategies, and students who use surface learning strategies would tend not to use deep strategies (Cano, 2007). Thus learning strategies are affected by pedagogical approach. Research has shown that shifting from traditional instructor-dominated pedagogy to a more learner-centered approach leads to deeper levels of understanding and meaning for the students (Lave \& Wegner, 1991; Tagg, 2003).

In their study of undergraduate students, Robinson and Hullinger (2008) found that successful students, defined as those who averaged an A grade, and students who were satisfied with their university experience reported higher levels of engagement. Further, these same students reported greater utilization of higher order thinking skills such as analysis, synthesis, and making judgments. Therefore, students reporting high levels of engagement also reported high levels of deep learning.

Researchers have often paired the factors of course value and learning in their study of student evaluations of teaching (Marsh \& Dunkin, 1997; Marsh \& Roche, 2000). When used in student evaluations of teaching, course value tends to include factors such as whether or not the course was challenging, whether the student learned something valuable, whether the course increased a student's interest in the subject matter, and whether or not the student learned the subject matter (Marsh, 1984). McKeachie (1997) also found a significant relationship between course workload, learning, and course value that supports Marsh's (1984) findings. A course that is designed to be challenging and of value to the student will generate deep learning strategies and, thus, deep learning.

In sum, cognitive engagement and course value are integral parts to the puzzle of creating the best possible learning experience for students. Students who are sufficiently engaged with learning course material and perceive the value of a course as high will have an overall positive learning experience. Students that perceive higher course value and are more engaged will be more likely to use deep learning strategies. Learning strategies associated with lower course value and less engagement contribute to surface learning. Therefore, this study hypothesizes that a student's 
level of cognitive engagement and the perception of course value affect deep and surface learning strategies (see Figure 1). Our hypotheses are as follows:

$\mathrm{H}_{1}$ : The greater the student's sense of engagement, the greater the student's use of deep learning strategies.

$\mathrm{H}_{2}$ : The lower the student's sense of engagement, the greater the student's use of surface learning strategies.

$\mathrm{H}_{3}$ : The greater the student's perception of course value, the greater the student's use of deep learning strategies.

$\mathrm{H}_{4}$ : The lower the student's perception of course value, the greater the student's use of surface learning strategies.

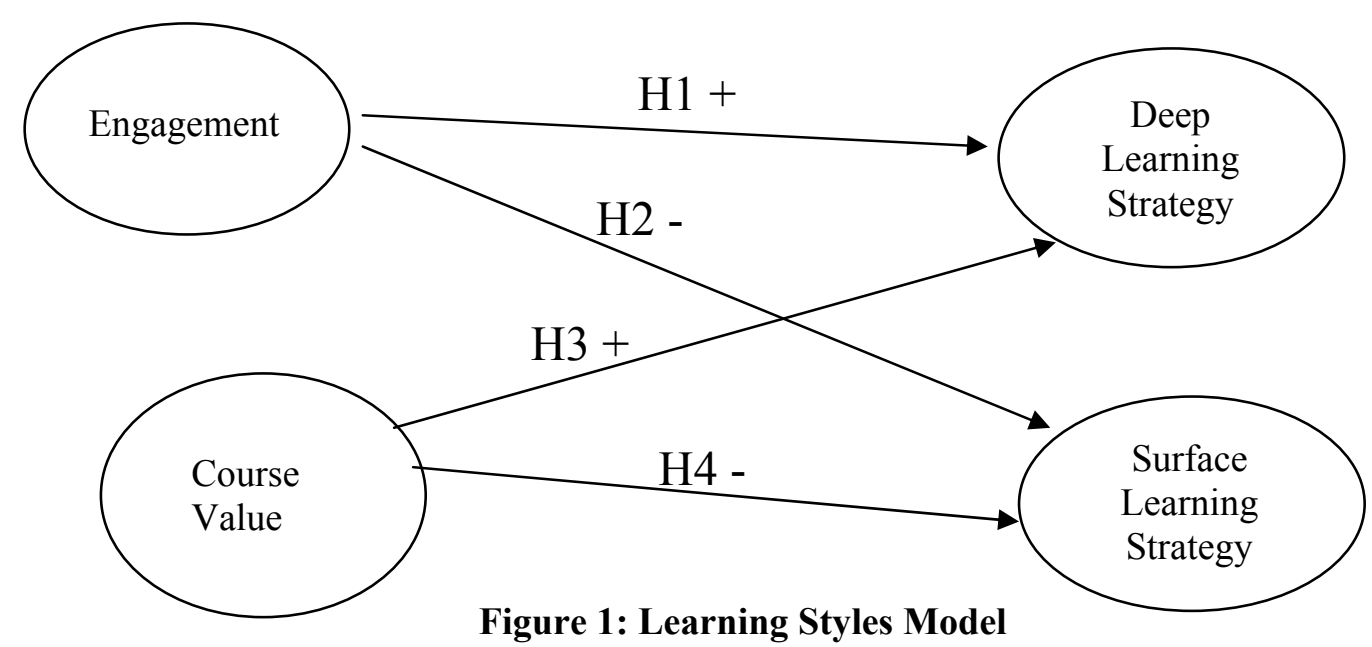

Methodology

\section{Participants}

The participants of this study consisted of 191 students enrolled in courses taught in the School of Information Technology at Macon State College, a medium sized (6,431 students), nonresidential state college in the southeastern United States. The course sections involved in this study were taught over a period of three academic semesters - spring semester 2007, summer semester 2007, and fall semester 2007. Eight different courses attended mainly by information technology and business majors were included. The courses were taught by six different faculty members. Eighty-one (81) of the course sections were online and 110 were face-to-face. No significant differences in the variables of interest were found between online and face-to-face classes or between upper (junior and senior) and lower (freshman and sophomore) division courses.

\section{Instrumentation}

The instrumentation used in this study (see Appendix) was developed using scales from previous studies. Our course value items came from Appleton, Christenson, Kim, and Reschly's (2006) scale on control and relevance of school work, which had shown good convergent and discriminant validity (Appleton et al., 2006). Additional course value items came from Marsh and Cooper's (1981) scale on students' evaluation of teaching effectiveness, which showed good con- 
struct validity as evaluated by a factor analysis of students' evaluation of teaching effectiveness scores. Cognitive engagement items were obtained from Handelsman, Briggs, Sullivan, and Towler's (2005) scale on student course engagement, which also showed good convergent and discriminant validity. Deep and surface learning strategy scales were developed from Biggs, Kember, and Leung (2001). Confirmatory factor analysis indicated good construct validity (Biggs et al., 2001). In total, twenty six items were developed. For all of the questions, except those measuring learning strategies, students responded to a Likert scale, which ranged from a low of 1 (very strongly disagree) to a high of 7 (very strongly agree). On the questions measuring learning strategies, students responded to a Likert scale, which ranged from a low of 1 (never or rarely) to a high of 5 (always or almost always). All questions were self perceptions and worded to obtain the students' perceptions of their own course value, engagement and learning strategies.

\section{Procedures}

After obtaining IRB approval, the instrument was administered electronically at the end of each of the three semesters. The students were guaranteed confidentiality of responses and assured that their professor would not be given responses by individual or be able to identify them.

A factor analysis with varimax rotation was performed on the items. The expected factors resulted: perceived course value, student engagement, deep learning strategy, and surface learning strategy. Using data from the sample of 190 students who completed the instrument, Cronbach's alpha was calculated for perceived course value $(\alpha=.946)$, student engagement $(\alpha=.949)$, deep learning $(\alpha=.876)$, and surfacing learning $(\alpha=.753)$. As these numbers reveal, there was an acceptable degree of internal consistency in the responses to each set of items.

Scales for perceived course value, student engagement, deep learning strategy, and surface learning strategy were formed by averaging responses on the Likert scales for each respondent on the respective items for each construct.

\section{Results}

The descriptive statistics for, and the correlation between, course value, engagement, deep learning strategy, and surface learning strategy are presented in Table 1. Statistical analysis reveals that there is a positive and significant correlation, at the $\mathrm{p}<.001$ level, between perceived course value and deep learning strategy and between student engagement and deep learning strategy. In addition, a negative and significant correlation, at the $\mathrm{p}<.001$ level, exists between perceived course value and surface learning strategy. These findings suggest that a deep learning strategy occurs when students perceive that they are engaged in the learning process and their perceived value of the course content is high. These results also show that a surface learning strategy occurs when the student's perceived value of the course is low. As expected, deep learning strategy and surface learning strategy are negatively correlated with each other. 
Table 1: Spearman Correlations and Descriptive Statistics among Perceived Course Value, Student Engagement, Deep Learning Strategy, and Surface Learning Strategy

\begin{tabular}{lcccc}
\hline & 1 & 2 & 3 & 4 \\
\hline 1. Perceived Value & --- & & & \\
2. Course Engagement & $.620^{* * *}$ & --- & & \\
3. Deep learning strategy & $.555^{* * *}$ & $.386^{* * *}$ & --- & -- \\
4. Surface learning strat- & $-.293^{* * *}$ & -.074 & $-.439^{* * *}$ & 2.24 \\
\hline M & 5.22 & 5.02 & 2.90 & .89 \\
SD & 1.41 & 1.43 & .90 & 1 to 5 \\
Scale Min/Max Values & 1 to 7 & 1 to 7 & 1 to 5 & .753 \\
Cronbach's $\alpha$ & .946 & .949 & .876 & \\
\hline$* * * \mathrm{p}<.001$ & & & &
\end{tabular}

\section{Limitations}

The limitations of this research include the use of a convenience sample. The sample was composed of students enrolled in information technology courses taught by instructors in the School of Information Technology at a regional Southern state college in the U.S. Future research should include random sampling to include a more diverse group of students in other areas of study and other regions of the country or world.

In addition, causality cannot be confirmed, since the study was cross-sectional. Whether engagement and course value influence a deep learning strategy or a surface learning strategy can only be confirmed through a longitudinal study.

\section{Conclusion and Implications}

The results of this study suggest that students who perceive they are more engaged in class activities are more likely to report greater use of deep learning strategies. In addition, students who have a positive view of course value will report greater use of deep learning strategies. Also, students who have a negative view of the value of the course will report less use of surface learning strategies.

While there is much research to suggest that engagement is a way to help students learn, the findings of this study show that course value has a stronger correlation with a deep learning strategy than engagement does. Perceived course value is also associated with a reduced tendency toward use of a surface learning strategy. Faculty therefore should not ignore the importance of perceived value as a key factor for promoting deep learning and controlling surface learning. Our measure of course value is consistent with Hulleman (2007), where course value can be intrinsic, where the course is enjoyable and fun, or utilitarian, where the course is perceived as useful or important to other tasks or aspects of an individual's life. Tying the course to the "real world," the student's future career or personal life should stimulate the students' perceived value of the course. Interesting and challenging assignments should also enhance perceived course value.

Also of interest is the strong correlation between perceived course value and perceived engagement. While our study does not allow us to know the direction of causality, it is easy to imagine causality in both directions: i.e., that perceived course value may increase engagement, and that effectively used engagement techniques may increase perceived course value. There may also be 
a third or spurious variable, such as structure of the class or teaching style, which affects both variables.

However, the finding of a correlation between perceived course value and perceived engagement is consistent with Hidi and Renninger (2006), who argue that the influence of the perception of course value is not only immediate upon the student's exposure to the task but also necessary over time to encourage development of cognitive engagement and individual motives toward deeper learning. The implications for educators is that enhancing perceptions of course value, in the form of intrinsic and utilitarian motives for learning, is important at not only the initial assignment of a learning task, but also important throughout the learning of the concept. If Hidi and Renninger's (2006) theory is true, then ongoing interventions of course value should lead to enhanced student engagement.

The important role of perceived value in this study suggests that it would be fruitful for future research to examine how to enhance the perceived value of the course to the student. Intrinsic or enjoyable activities have often been described as problem or inquiry based and, while often discipline specific, may include college-level activities such as student-created crossword puzzles or electronic voting systems that encourage deeper learning (Draper, 2009). Activities that are seen as useful have been described as relevant to the student's life or future. Use of role-playing, simulated virtual environments, or case-based analysis may help in showing relevance, but further research is needed to show these connections between classroom tasks and perceived course value.

The students' reported perceived engagement, as suggested by previous studies, was also correlated to deep learning strategies while having no effect on surface learning strategies. Thus engaging students via discussions, questions and answers, and idea sharing within an organized class structure should enhance engagement and deep learning. Keeping students focused on the material is a consistent theme underlying the hundreds of articles suggesting ways to improve engagement.

That surface learning strategies have no significant relationship to engagement while deep learning strategies do is consistent with the idea that a surface learning strategy is a survival technique - the student is simply trying to pass the course with minimal effort. Since engagement has no relationship to a surface learning strategy, whereas perceived course value does, the importance of course value in getting the unmotivated student to expend effort to go beyond surface learning is an important finding of this study. If the role of an instructor is to have all students learn the material, regardless of motivation level, instructors should focus on enhancing perceptions of course value.

The results of this study also suggest a possible enhancement to existing informing science models - the information filter model proposed by Jamieson \& Hyland (2006) and the later Client Resonance Model proposed by Gill (2008). Both models propose that a series of filters affects a student's (client's) knowledge at three levels, from high level concepts at one extreme to lower, more automated operators at the other extreme. The results of this study suggest that the effects of the "Attention" and "Motivation" filters are substantially more complex than the Client Resonance model suggests. The "Motivation" filter in Gill's model affects Level 3 knowledge only. The results of this study, however, imply that when motivation to engage is high, we are much more likely to experience structural changes to mental models (the higher levels of the Client Resonance Model) whereas when motivation to engage is low, students will attempt to make changes on lower levels - in other words, clients will attempt to incorporate the information without fundamentally altering what they already know.

In sum, since both perceived course value and engagement positively affect deep learning strategies, future studies may wish to identify other variables that may influence them. By understand- 
ing and enhancing perceived value and engagement, the ultimate goal of enhancing deep learning should result.

\section{References}

Appleton, J. J., Christenson, S. L., Kim, D., \& Reschly, A. L. (2006). Measuring cognitive and psychological engagement instrument. Journal of School Psychology, 44, 427-445.

Biggs, J. B. (1987). Student approaches to learning and studying. Hawthorn, Victoria: Australian Council for Educational Research.

Biggs, J. B. (1989). Approaches to the enhancement of tertiary teaching. Higher Education Research and Development, 8, 7-25.

Biggs, J. B., Kember, D., \& Leung, D. (2001). The revised two-factor study process questionnaire: R-SPQ2F. British Journal of Educational Psychology, 71(1), 133-149.

Bishop, P. A., \& Pflaum, S. W. (2005). Students' perceptions of action, relevance and pace. Middle School Journal, 36(4), 4-12.

Bowden, J., \& Morton, F. (1998). The university of learning. London, England: Kogan Page.

Cano, F. (2007). Approaches to learning and study orchestrations in high school students. European Journal of Psychology of Education, 22(2), 131-151.

Cohen, E. B. (2009). A philosophy of Informing Science. Informing Science: the International Journal of an Emerging Transdiscipline, 12, 1-15. Retrieved Mar. 6, 2009 from http://inform.nu/Articles/Vol12/ISJv12p001-015Cohen399.pdf

Conrad, R., \& Donaldson, J. A. (2004). Engaging the online learner: Activities and resources for creative instruction. San Francisco: Jossey-Bass.

Corno, L., \& Mandinach, E. B. (1983). The role of cognitive engagement in classroom learning and motivation. Educational Psychologist, 18 (2), 88-108.

Draper, S. W. (2009). Catalytic assessment: Understanding how MCQs and EVS can foster deep learning. British Journal of Educational Technology, 40(2), 285-293.

Entwistle, N. J. (1981). Styles of learning and teaching: An integrated outline of educational psychology for students, teachers and lecturers. Chichester: Wiley.

Gill, T. G. (2008). The single client resonance model: Beyond rigor and relevance. Informing Science: the International Journal of an Emerging Transdiscipline, 11, 281-310. Retrieved August 20, 2009 from http://inform.nu/Articles/Vol11/ISJv11p281-310Gill222.pdf

Handelsman, M. M, Briggs, W. L., Sullivan, N., \& Towler, A. (2005). A measure of college student course engagement. The Journal of Educational Research, 98(3), 184-191.

Hidi, S., \& Renninger, K. A. (2006). The four-phase model of interest development. Educational Psychologist, 41(2), 111-127.

Hulleman, C. S. (2007). The role of utility value in the development of interest and achievement. Unpublished Doctoral Dissertation. University of Wisconsin-Madison.

Jamieson, K., \& Hyland, P. (2006). Good intuition or fear and uncertainty: The effects of bias on information systems selection decisions. Informing Science: the International Journal of an Emerging Transdiscipline, 9, 49-69. Retrieved from http://inform.nu/Articles/Vol9/v9p049-069Jamieson60.pdf

Jurow, A. S. (2005). Shifting engagements in configured worlds: Middle school mathematics students' participation in an architectural design project. The Journal of the Learning Sciences, 14(1), 35-67.

Lave, J., \& Wegner, E. (1991). Situated learning: Legitimate peripheral participation. New York: Cambridge University Press. 
Marsh, H. W. (1984). Students' evaluations of university teaching: Dimensionality, reliability, validity, potential biases, and utility. Journal of Educational Psychology, 76, 707-754.

Marsh, H. W., \& Cooper, T. L. (1981). Prior subject interest, students' evaluations, and instructional effectiveness. Multivariate Behavioral Research, 16, 83-104.

Marsh, H. W., \& Dunkin, M. J. (1997). Students' evaluations of university teaching: A multidimensional perspective. In R. P. Perry \& J. C. Smart (Eds.), Effective teaching in higher education: Research and practice (pp. 241-320). New York: Agathon Press.

Marsh, H. W., \& Roche, L. A. (2000). Effects of grading leniency and low workload on students' evaluations of teaching: Popular myth, bias, validity, or innocent bystanders? Journal of Educational Psychology, 92, 202-228.

Marton, F., \& Säljö, R. (1976). On qualitative differences in learning I: Outcome and process. British Journal of Educational Psychology, 46, 4-11.

McKeachie, W. J. (1997). Good teaching makes a difference-And we know what it is. In R. P. Perry \& J. C. Smart (Eds.), Effective teaching in higher education: Research and practice (pp. 396-411). New York: Agathon.

Mitchell, M. (1993). Situational interest: Its multifaceted structure in the secondary school mathematics classroom. Journal of Educational Psychology, 85, 424-436.

Ramsden, P. (2003). Learning to teach in higher education. London: RoutledgeFalmer.

Richardson, J. C., \& Newby, T. (2006). The role of students' cognitive engagement in online learning. The American Journal of Distance Education, 20(1), 23-37.

Robinson, C., \& Hullinger, H. (2008, November). New benchmarks in higher education: Student engagement in online learning. Journal of Education for Business, 84(2), 101-109.

Tagg, J. (2003). The learning paradigm college. Boston: Anker.

\section{Measures}

\section{Appendix}

Value 1: The course was challenging/stimulating

Value 2: I learned something valuable

Value 3: The course increased my interest in the subject

Value 4: The course helped me to learn/understand the subject matter

Value 5: The readings/text were valuable

Value 6: The assignments added to course understanding

Value 7: What I am learning in this class will be important to my future.

Value 8: The assignments gave me a sense of the application of this course to the "real world."

Engaged 1: The class encouraged discussion

Engaged 2: Students shared their ideas/knowledge

Engaged 3: The class encouraged questions and answers

Engaged 4: The class encouraged expression of ideas

Engaged 5: I have felt very involved or engaged in this class

Engaged 6: I have felt more involved or engaged in this class than in other courses I've taken

Deep 1: I find that at times studying gives me a feeling of deep personal satisfaction

Deep 2: I feel that virtually any topic can be highly interesting once I get into it.

Deep 3: I find most new topics in this class interesting and often spend extra time trying to obtain more information about them.

Deep 4: I find that studying topics in this class can at times be as exciting as a good novel or movie.

Deep 5: I test myself on important topics in this class until I understand them completely. 
Deep 6: I work hard at my studies because I find the material interesting.

Deep 7: I spend a lot of my free time finding out more about interesting topics which have been discussed in the class.

Deep 8: I come to most classes with questions in mind that I want answering.

Surface 1: My aim is to pass the course while doing as little work as possible.

Surface 2: I do not find my course very interesting so I keep my work to the minimum.

Surface 3: I generally restrict my study to what is specifically set as I think it is unnecessary to do anything extra.

Surface 4: I make a point of looking at most of the suggested readings that go with the lectures. (Reverse)

\section{Biographies}

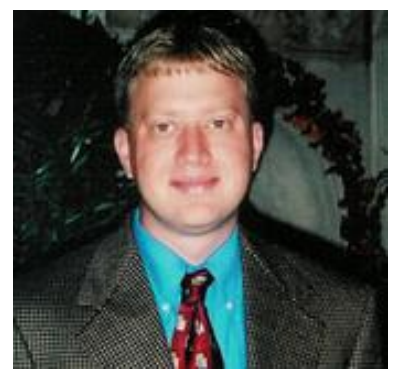

Kevin Floyd is an assistant professor of Information Technology in the School of Information Technology at Macon State College. He teaches in the areas of web development, web programming, and application development. His current research interests are in the areas of open source technologies, web accessibility, and student learning and engagement strategies.

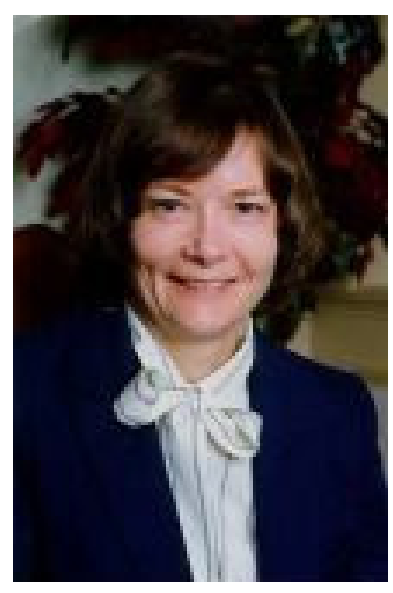

Dr. Susan J. Harrington is a professor in the School of the Information Technology at Macon State College, Macon, Ga. From 19942005, she was a professor of Information Systems at Georgia College \& State University and from 1986-1994, a professor at Kent State University - Stark campus. She also has 13 years of information systems experience in large organizations where she was a systems analyst, project manager, and manager. Her interests include ethical decision making in organizations, IT adoption and diffusion, telecommuting, information requirements analysis, trust, and corporate culture. She has published in MIS Quarterly, e-Service Journal, IEEE Transactions on Professional Communication, Journal of Business Ethics, DATA BASE for Advances in Information Systems, Information \& Organisation, and Academy of Management Executive, as well as other management journals.

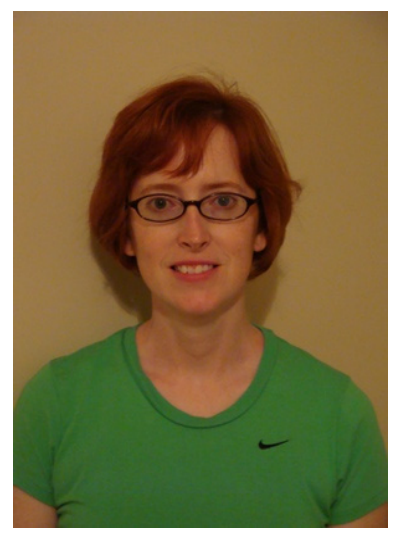

Julie Santiago is an Assistant Professor in the School of Information Technology at Macon State College. She is currently pursuing her Ed.D. at Georgia Southern University. Her areas of teaching specialization include programming, software security and information systems management. 